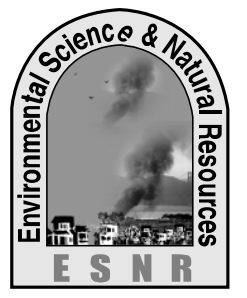

J. Environ. Sci. \& Natural Resources, 7(1): 227- 232, 2014

ISSN 1999-7361

\title{
Biochemical Composition and Shelf Life Study of Mixed Fruit Juice from Orange \& Pineapple
}

\author{
M. A. Islam, I. Ahmad, S. Ahmed, A. Sarker
}

Department of Food Engineering and Tea Technology,

Shahjalal University of Science \& Technology, Sylhet-3114, Bangladesh

\begin{abstract}
In present study, fruit juice has been produced in different ratio of pineapple and orange juice. Juices were pasteurized at $97^{\circ} \mathrm{C}$ for 5 mins and stored for 35 days in PET bottles at refrigerated temperature. The TSS and pH of the different types of juice were found in the range of 7.73 to 8.53 and 4.33 to 4.53 respectively. Maximum acidity $(0.785 \%)$ and vitamin $\mathrm{C}$ (37.1 $\mathrm{mg} / 100 \mathrm{ml}$ ) were found in the sample A (in a ratio 1:1). Aerobic plate count was found within the range of $\left(92 \times 10^{6}\right.$ to $\left.233 \times 10^{6}\right)$ $\mathrm{cfu} / \mathrm{ml}$. The produced juice blends were subjected to chemical and sensory evaluation at one week interval for five weeks storage time. The chemical analysis showed that, there is a gradual decrease in titratable acidity and Vitamin-C along the storage period. TSS and pH increased progressively during storage period. The mean overall acceptability scores of more than 8 for juice samples indicated the commercial scope for manufacturing good and nutritious pineapple juice blended with orange juice. From all the analysis, it can be observed that the juice blend can be kept conveniently for three weeks without preservatives and 28 days with sodium benzoate at the rate of $0.6 \mathrm{mg} / \mathrm{L}$.
\end{abstract}

Key words: Juice; Shelf life; Orange; Pineapple

\section{Introduction}

In Bangladesh, different kinds of seasonal fruits are available which are reach in food nutrients, vitamins and minerals particularly, some seasonal citrus fruits are very delicious and nutrias. Pineapple (Ananas comosus) has long been one of the most popular of the non-citrus tropical and subtropical fruits around the world, largely because of its attractive flavor and refreshing sugar-acid balance and is consumed as fresh fruits, juice and others (Bartolome et al., 1995). Pineapple was reported to contain polyphenolic compounds and also possess antioxidant activity (Hossain and Rahman, 2011). Studies show that compounds such as phenolics and flavonoids are responsible for providing antioxidant activity (Kahkonen et al., 1999; Alothman et al., 2009; Mhatre et al., 2009; Danino et al., 2009). Raw pineapple juice contains almost all vitamins and minerals essential for the digestive system. Pineapple juice contains a mixture of protein-digesting enzymes called Bromelain. Bromelain is an anti-inflammatory agent. Juice extracted from pineapple can be processed into many forms such as concentrated juice, mixed juice and single strength juice. Orange (Citrus cinensis) on the other hand, is a distinguished, widely consumed fruit, particularly appreciated for its fresh flavor, vitamin $\mathrm{C}$, and its natural antioxidants source having health benefits. Orange juice is rich in vitamin $\mathrm{C}$, folic acid, potassium and excellent source of bioavailable antioxidant phytochemicals. Fruit juices are important trade commodities in most countries (Vasavada, 2003). Juices are available in their natural concentrations or in processed forms.
Juices are fat-free, nutrient-dense beverages rich in vitamins, minerals and naturally occurring phytonutrients that contribute to good health (Franke et al. 2005). Fruit juice blends can be produced from various fruits in order to combine all the basic nutrients present in these different fruits. This usually gives a better quality juice nutritionally and organoleptically. Moreover, one could think of a new product development through blending in the form of a natural health drink, which may also be served as an appetizer. Generally, the shelf life of fresh juice is restricted by enzyme and microorganism activity. Spoilage of fruit juices is mainly due to the presence of osmophillic microflora (Tahiri et al., 2006). This microflora (yeasts) causes fermentation and produce a buttermilk-like off-flavour (Tournas et al., 2006). An effective method of fruit preservation should retain the original characteristics of fruit as convenient as possible. Presently, thermal pasteurisation is considered the most effective technology in inactivating microorganisms and enzymes to extend product shelf life (Noci et al., 2008). The present study was carried out for the development of mixed fruit juice from orange and pineapple in different ratio and establishment of product shelf life and quality evaluation during storage.

\section{Materials \& Methods}

\subsection{Sample collection}

The fully ripened and fresh Orange (Citrus sinesis) \& Pineapple (Ananas comosus) were collected from the local market of Sylhet. 


\subsection{Preparation of juice}

The fully ripened and fresh orange and pineapple fruits were washed thoroughly with clean water to remove dirty material, dust, pesticide etc. The collected pineapple and orange were peeled off and cut into pieces and remove the seeds. Then, juice was extracted using multi fruit juice extracting machine.
The juice was filtered using a 500 micro aperture stainless steel sieve screen. The percentage of orange and pineapple juice for the development of four different types of product $(\mathrm{A}, \mathrm{B}, \mathrm{C}, \mathrm{D})$ are given in the table 1 . Sodium benzoate was added at a level of $0.6 \mathrm{~g} / 1000 \mathrm{ml}$ in sample D and mixed thoroughly with sterilized glass rod and spoon.

Table 1: Formulation for mixed fruit juice.

\begin{tabular}{cccc}
\hline Products & Orange $(\%)$ & Pineapple $(\%)$ & Sodium benzoate $(\mathrm{g} / 1000 \mathrm{ml})$ \\
\hline Sample A & 50 & 50 & 0 \\
\hline Sample B & 30 & 70 & 0 \\
\hline Sample C & 10 & 90 & 0 \\
\hline Sample D & 50 & 50 & 0.6
\end{tabular}

\subsection{Thermal pasteurisation treatment}

Thermal pasteurization was performed by heating the mixed juice at $97^{\circ} \mathrm{C}$ for 5 mins. The temperature of the juice during the heating process was monitored using a thermocouple. The pasteurised juices were filled in sterilized PET bottles and capped with sterilized caps. Then all the samples were cooled and stored at refrigerated temperature $\left(4 \pm 1^{0} \mathrm{C}\right)$ for 35 days.

\subsection{Chemical analysis of fruit juice}

Total soluble solids (TSS) content of a solution is determined by the index of refraction. This is measured using a refractometer, and is referred to as the degrees Brix. $\mathrm{pH}$ was measured by a $\mathrm{pH}$ meter. Vitamin $\mathrm{C}$ or Ascorbic acid was determined by using the official method of analysis. (AOAC, 1990). The acidity was determined by titration using standard sodium hydroxide solution and expressed as anhydrous citric acid (Ranganna S, 2003).

\subsection{Microbiological analysis of fruit juice}

For the assessment of microbiological quality of juice, Enumeration of Aerobic Plate Count (APC), total fugal count were performed according to ISO standard method (ISO-4833:2003(E), Microbiology of food and animal feeding stuffs-Horizontal method for the enumeration of microorganisms- Colony-count technique at $30^{\circ} \mathrm{C}$ ). Enumeration of APC was done by serial dilution technique followed by pour plate method and plate count agar was used.

\subsection{Sensory analysis}

Panel of ten judges was selected from the postgraduate students and teaching staff of the Institute who were supposed to be organoleptically familiar with beverages assessment. Sensory evaluation (color, flavor, taste and overall acceptability) of preserved orange juice was carried out using a 9 point hedonic scale. The hedonic scale was ranked as; like extremely to very much (8-9 scores), like moderately to like slightly (5-7 scores), neither like nor dislike to dislike slightly-dislike moderately (2-4 scores) and dislike very much to dislike extremely (0-1 score).

1.7.

\section{Statistical analysis}

The data obtained were analyzed and interpreted by analysis of variance (ANOVA) and Tukey means comparison test at a level of $5 \%$ of significance, using SPSS Version 20.0 software (SPSS Inc., USA). Values were presented as mean \pm standard deviations of 3 observations.

\section{Results and Discussion}

\subsection{Chemical analysis}

The juices were analyzed for TSS, pH, Acidity and vitamin-C. TSS of the different types of juice was found in the range of 7.73 to 8.56. Out of four samples maximum TSS was found in the sample D. The $\mathrm{p}^{\mathrm{H}}$ of the sample was found in the range of 4.33 to 4.53 . Maximum acidity was found in the sample A (50\% orange and $50 \%$ pineapple juice) which was $0.785 \%$ due to higher proportion of orange as orange is more acidic than pineapple. Awsi Jan \& Er. Dorcus Masih (2012) reported that the titrable acidity content of pineapple and orange juice with different ratio vary from 0.83 to 0.54 , which is similar to our present study. Vitamin-C content $(37.1 \mathrm{mg} / 100 \mathrm{ml})$ of the sample A was significantly $(\mathrm{P}<0.05)$ higher than other samples. So sample A is nutritionally rich than other samples. The proximate composition of mixed fruit juice was more or less similar with the values reported by Awsi Jan \& Er. Dorcus Masih (2012). 
Table 2: The proximate composition of the prepared juice

\begin{tabular}{ccccc}
\hline Sample & TSS $\left({ }^{\circ}\right.$ Brix $)$ & $\mathrm{pH}$ & Acidity $(\%$ of citric acid $)$ & Vitamin C \\
\hline Sample A & $8.53 \pm 0.35^{\mathrm{a}}$ & $4.33 \pm 0.05^{\mathrm{a}}$ & $0.785 \pm 0.011^{\mathrm{a}}$ & $37.1 \pm 0.95^{\mathrm{a}}$ \\
Sample B & $8.23 \pm 0.35^{\mathrm{b}}$ & $4.53 \pm 0.05^{\mathrm{b}}$ & $0.717 \pm 0.009^{\mathrm{b}}$ & $33.3 \pm 1.05^{\mathrm{b}}$ \\
Sample C & $7.73 \pm 0.30^{\mathrm{c}}$ & $4.50 \pm 0.00^{\mathrm{b}}$ & $0.624 \pm 0.008^{\mathrm{c}}$ & $30.9 \pm 0.53^{\mathrm{c}}$ \\
Sample D & $8.56 \pm 0.35^{\mathrm{d}}$ & $4.43 \pm 0.05^{\mathrm{ab}}$ & $0.761 \pm 0.006^{\mathrm{d}}$ & $34.6 \pm 0.85^{\mathrm{b}}$ \\
\hline
\end{tabular}

Values expressed as the mean \pm standard deviation. The same letter in the same colum indicates no significant difference at the level of $5 \%$ significance.

\subsection{Microbial analysis}

Two parameters were studied viz. Aerobic plate count and Total fungal count for the microbiological quality analysis of juice. The result of APC and Total fungal

Table 3: Microbial analysis of the prepared juice

\begin{tabular}{ccc}
\hline Product & APC $(\mathrm{cfu} / \mathrm{ml})$ & $\begin{array}{c}\text { Total fungal } \\
(\mathrm{cfu} / \mathrm{ml})\end{array}$ \\
\hline Sample A & 167 & 43 \\
Sample B & 173 & 55 \\
Sample C & 233 & 49 \\
Sample D & 92 & 19 \\
\hline
\end{tabular}

\subsection{Storage studies of mixed fruit juice}

The produced juice blends were subjected to chemical and sensory evaluation at one week interval for five weeks storage time. Table 4 shows the effects of storage time on chemical composition and organoleptic quality of orange and pineapple juices. TSS increased with gradual passage of storage time, which might be due to hydrolysis of polysaccharides into monosaccharide and oligosaccharides. At first day TSS of the samples were ranged from 7.7 to 8.5 , which were gradually increased to 9.8 to 10.3 during 35 days of storage. Similar results were also reported by Deka and Sethi (2001). Bull et al. (2004) also reported that the Brix of thermally processed Valencia and Navel orange juice did not change significantly during storage time at $4^{0} \mathrm{C} . \mathrm{pH}$ is one of the important quality characteristics that describes the stability of bioactive compounds in fruit juice (Sanchez-Moreno et al., 2006). There was a significant increase in $\mathrm{pH}$ during storage, which affects the organoleptic quality of juice. This might be due to decrease in titrable acidity, as acidity and $\mathrm{pH}$ are inversely proportional to each other. It was observed that the maximum $\mathrm{pH}$ (5.6) was recorded in the sample D. During storage maximum increase $(27.27 \%)$ was observed in the sample A and sample D. Similar result was found by Dhaliwal and Hira (2001), where maximum increase count are documented in Table 3. The APC in juice sample was found range from $92 \mathrm{cfu} / \mathrm{ml}$ to $233 \mathrm{cfu}$ $/ \mathrm{ml}$. Total fungal count was ranged from $19 \mathrm{cfu} / \mathrm{ml}$ to $55 \mathrm{cfu} / \mathrm{ml}$.

of pH was $29.9 \%$. Cortes et al. (2008) similarly found that $\mathrm{pH}$ increased significantly in the fresh highpressurised and pasteurised orange juice during 7 weeks of storage at $2^{0} \mathrm{C}$ and. These researchers stated that the increased $\mathrm{pH}$ values in these juices were caused by the microorganisms that caused juice spoilage. Del Caro et al. (2004) also found a pH increase in citrus segments and juices stored at $4^{0} \mathrm{C}$. Titrable acidity was decreased during storage. This might be due to conversion of acids into salts and sugars by enzymes particularly invertase. During storage maximum decrease was observed in the sample B (15.62\%) while minimum decrease was observe in the sample D $(5.78 \%)$. Similar result was found by Tiwari (2000) in guava and papaya blended RTS beverage and Dhaliwal and Hira (2001) in carrot juice blends. Ascorbic acid (vitamin C) is an important nutrient that possesses antioxidant ability and provides the protection against free radicals (Esteve et al., 2005). It is also considered an indicator of the nutritional quality of juices (Bull et al., 2004). Storage temperature, type of processing and packaging materials affect the rate of ascorbic acid degradation during storage (Ayhan et al., 2001). The ascorbic acid content of the juice decreased significantly $(\mathrm{p}<0.05)$ during storage with the advancement of storage period, which was probably due to the fact that ascorbic acid being sensitive to oxygen, light and heat was easily oxidized in presence of oxygen by both enzymatic and non-enzymatic catalyst (Davey et al., 2000). Thermally pasteurised juice retained $50 \%$ of their initial ascorbic acid up to 3 Weeks. Juices with $50 \%$ retention of their initial Vitamin C are considered as the end of their shelf life (Shaw, 1992). Organoleptic parameters like color, flavor, and taste of the juices were acceptable up to 21days of storage. All the products except sample D were deteriorated in quality like change in color and 
objectionable taste, development of off flavor after 21 days but sample D was good up to 28 days which was

preserved with sodium benzoate.

Table 4: Storage study of mixed fruit juice.

\begin{tabular}{|c|c|c|c|c|c|c|c|c|}
\hline $\begin{array}{l}\text { Storage } \\
\text { time }\end{array}$ & $\begin{array}{l}\text { Sample } \\
\text { Code }\end{array}$ & TSS & $\mathrm{pH}$ & $\begin{array}{l}\text { Acidity (\% of } \\
\text { citric acid) }\end{array}$ & $\begin{array}{l}\text { Vitamin C } \\
(\mathrm{mg} / 100 \mathrm{ml})\end{array}$ & Color & Flavor & Taste \\
\hline \multirow{4}{*}{ Day 0} & A & 8.5 & 4.3 & 0.785 & 37.1 & Orange & Fresh & Good \\
\hline & B & 8.2 & 4.5 & 0.717 & 33.3 & Orange & Fresh & Good \\
\hline & $\mathrm{C}$ & 7.7 & 4.5 & 0.624 & 30.9 & Orange & Fresh & Good \\
\hline & $\mathrm{D}$ & 8.5 & 4.4 & 0.761 & 34.6 & Orange & Fresh & Good \\
\hline \multirow{4}{*}{ Day 7} & A & 8.7 & 4.4 & 0.754 & 31.5 & Orange & Fresh & Good \\
\hline & B & 8.5 & 4.7 & 0.689 & 27.3 & Orange & Fresh & Good \\
\hline & $\mathrm{C}$ & 8.2 & 4.6 & 0.608 & 25.1 & Orange & Fresh & Good \\
\hline & $\mathrm{D}$ & 9.1 & 4.5 & 0.751 & 28.7 & Orange & Fresh & Good \\
\hline \multirow{4}{*}{ Day 14} & A & 9 & 4.6 & 0.737 & 25.4 & Orange & Fresh & Good \\
\hline & B & 8.8 & 4.9 & 0.667 & 22.6 & Orange & Fresh & Good \\
\hline & $\mathrm{C}$ & 8.9 & 4.7 & 0.578 & 19.8 & Orange & Fresh & Good \\
\hline & $\mathrm{D}$ & 9.3 & 4.7 & 0.744 & 24.1 & Orange & Fresh & Good \\
\hline \multirow{4}{*}{ Day 21} & A & 9.4 & 4.9 & 0.722 & 20.7 & Orange & Fresh & Good \\
\hline & B & 9.5 & 5.1 & 0.648 & 18.4 & Orange & Fresh & Good \\
\hline & $\mathrm{C}$ & 9.5 & 5.1 & 0.558 & 15.2 & Orange & Fresh & Good \\
\hline & $\mathrm{D}$ & 9.7 & 5 & 0.732 & 18.8 & Orange & Fresh & Good \\
\hline \multirow{4}{*}{ Day 28} & A & 9.6 & 5.1 & 0.691 & 16.3 & Orange & Off flavor & Sour \\
\hline & B & 9.8 & 5.2 & 0.621 & 13.2 & Light orange & Off flavor & Good \\
\hline & $\mathrm{C}$ & 9.7 & 5.2 & 0.539 & 11.4 & Light orange & Off flavor & Sour \\
\hline & $\mathrm{D}$ & 10.1 & 5.3 & 0.724 & 15.2 & Orange & Fresh & Good \\
\hline \multirow{4}{*}{ Day 35} & A & 9.8 & 5.5 & 0.688 & 12.6 & Light orange & Off flavor & Sour \\
\hline & B & 10.2 & 5.3 & 0.605 & 8.7 & Light orange & Off flavor & Sour \\
\hline & $\mathrm{C}$ & 9.9 & 5.4 & 0.524 & 6.5 & Light orange & Off flavor & Sour \\
\hline & $\mathrm{D}$ & 10.3 & 5.6 & 0.717 & 11.8 & Light orange & Off flavor & Sour \\
\hline
\end{tabular}

\subsection{Sensory evaluation of the mixed fruit juice}

Table 5 shows the mean sensory score of the blended juice during storage. The evaluations were done for color, flavor, taste and overall acceptability. The color changed in week 4 as shown in the Table 4 . The color change within the storage period may be due to the microbiological and chemical reactions that might have occurred. Flavor is a combination of various sensations derived from foods. Flavor was constant for the first three weeks and the changes were noticed in the fourth week. On the taste and overall acceptability, the orange and pineapple juice was well accepted till the third weeks after which it decreases very rapidly. The intention was to incorporate the maximum possible quantity of pineapple juice in the juice mixture with higher sensory scores. It was observed that the highest sensory score was obtained with maximum incorporation of 50\% pineapple juice in the juice blend. Therefore, the ingredient compositions having $50 \%$ pineapple juice and $50 \%$ of orange juice were selected as optimum. 
Table 5: Mean sensory score of mixed fruit juice.

\begin{tabular}{cccccccc}
\hline & $\begin{array}{c}\text { Product } \\
\text { Type }\end{array}$ & Day 0 & Day 7 & Day 14 & Day 21 & Day 28 & Day 35 \\
\hline \multirow{5}{*}{ Color } & A & 8.2 & 7.9 & 7.5 & 6.5 & 4.6 & 3.2 \\
& B & 7.9 & 7.5 & 7.2 & 6.7 & 4.4 & 3.5 \\
& C & 7.8 & 7.5 & 7.4 & 6.2 & 4.2 & 3.8 \\
& D & 8 & 7.8 & 7.5 & 6.8 & 5.4 & 4.2 \\
\hline \multirow{5}{*}{ Flavor } & A & 8 & 7.6 & 7.6 & 6.8 & 3.5 & 3.3 \\
& B & 7.5 & 7.5 & 7 & 6.2 & 4 & 3 \\
& C & 7.4 & 7.5 & 6.8 & 6.2 & 3.7 & 3.2 \\
& D & 7.5 & 7.2 & 7.2 & 7 & 5.5 & 3.5 \\
\hline \multirow{5}{*}{ Taste } & A & 8.4 & 8.5 & 7.5 & 6.5 & 3.6 & 2.7 \\
& B & 8.2 & 7.9 & 7.2 & 6.4 & 5.4 & 3.2 \\
Occeptability & C & 7.5 & 6.9 & 7 & 5.8 & 4.6 & 3.8 \\
& D & 8.2 & 7.8 & 7.6 & 6.5 & 5.2 & 3.5 \\
\hline & A & 8.6 & 8.2 & 7.6 & 7 & 3.8 & 3.6 \\
& B & 8.4 & 8.1 & 7.3 & 6.8 & 3.3 & 3 \\
& C & 8.2 & 7.9 & 7 & 6.5 & 3.3 & 3.3 \\
& D & 8.5 & 8 & 7.5 & 6.9 & 6.6 & 4.2 \\
\hline
\end{tabular}

\section{Conclusion}

The present study indicates that a good quality value added product could be produced from orange and pineapple juice. The product quality was acceptable up to 21 days without any preservatives and 1 month with preservatives (sodium benzoate at the rate of $0.6 \mathrm{~g} / 1000 \mathrm{ml})$. So this juice could be stored for 21 days without any preservatives and 1 month with preservatives at refrigerated temperature. As this fruits have some special medicinal and nutritive value, it is assumed that it could fetch a good momentary value from the consumer. On the basis of above results revealed in the present study it may be concluded that the formulation of mixed fruit juice is possible to satisfy consumer taste and preferences. Therefore, the present study is a sign of bright prospect of processing mixed fruit juice.

\section{Acknowledgements}

The authors would like to thank the Department of Food Engineering \& Tea Technology, Shahjalal University of Science \& Technology, Sylhet-3114, Bangladesh for supporting this research project.

\section{Reference}

Alothman, M.; Bhat, R. and Karim, A.A. 2009a. Antioxidant capacity and phenolic content of selected tropical fruits from Malaysia, extracted with different solvents. Food Chemistry 115: 785-788.

A.O.A.C. (1990). Official Methods of Analysis, 15th Ed. Association of Official Analytical Chemists, Inc. USA.

Awsi, J. and Er.Dorcus, M. 2012. Development and quality evaluation of pineapple juice blend with carrot and orange juice', International Journal of Scientific and Research Publications, 2(8).

Ayhan, Z.; Teom, H.W.; Zhang, Q.H. and Min, D.B. 2001. Flavor, color and vitamin $C$ retention of pulsed electric fileds processed orange juice in different packaging materials. Journal of Agricultural and Food Chemistry, 49(2): 669-674.

Bull, M.K.; Zerdin, K.; Howe, E.; Goicoechea, D.; Paramanandhan, P.; Stockman, R.; Sellahewa, J.; Szabo, E.A.; Johnson, R.L. and Stewart, C.M. 2004. The effect of high pressure processing on the microbial, physical and chemical properties of Valencia 
and Navel orange juice. Innovative Food Science and Emerging Technologies 5: 135149.

Cortes, C.; Esteve, M.J. and Frigola, A. 2008. Color of orange juice treated by high intensity pulsed electric fields during refrigerated storage and comparison with pasteurized juice. Food control 19: 151-158.

Danino, O.; Gottlieb, H.E.; Grossman, S. and Bergman, M. 2009. Antioxidant activity of 1,3-dicaffeoylquinic acid isolated from Inulaviscosa. Food Research International 42(9): 1273-1280.

Davey, M.W.; Van, M.M.; Inze, D.; Sanmartin, M.; Kanellis, A.; Smimoff, N.; Benzie, L.J.J.; Strain, J.J.; Favell, D. and Fletcher, J. 2000. Plant L-ascorbic: chemistry, function, metabolism, bioavailable and effects of processing. Journal of the Science of Food and Agriculture 80(7): 825-860.

Deka, B.C. and Sethi,V.2001. Preparation of mixed fruit juice spiced RTS beverages. Ind. Fd. Packer, 42(3): 58-61.

Del, C.A.; Piga, A.; Vacca, V. and Agabbio, M. 2004. Changes of flavonoids, vitamin $\mathrm{C}$ and antioxidant capacity in minimally processed citrus segments and juices during storage. Food Chemistry 84: 99-105.

Dhaliwal, M. and Hira, K.C. 2001. Effect of storage on physico-chemical and nutritional characteristics of carrot-beet root and carrotblack carrot juices. Journal of Food Science Technology, 38(4): 343-347.

Esteve, M.J.; Frigola, A.; Rodrigo, C. and Rodrigo, D. 2005. Effect of storage period under variable conditions on the chemical and physical composition and colour of Spanish refrigerated orange juices. Food and Chemical Toxiology 43: 1413-1422.

Franke, A.A.; Cooney, R.V.; Henning S.M. and Custer, L.J. 2005. Bioavailability and antioxidant effects of orange juice components in humans. J Agric Food Chem., 53 (13): 5170-5178.

Hossain, M.A. and Rahman, S.M.M. 2011.Total phenolics, flavonoids and antioxidant activity of tropical fruit pineapple. Food Research International 44: 672-676.
Kahkonen, M.P.; Hopia, A.I. and Vuorela, H.J. 1999. Antioxidant activity of plant extracts containing phenolic compounds. Journal of Agricultural Chemistry 47: 3954-3962.

Mhatre, M.; Tilak-Jain, J.; De, S. and Devasagayam, T.P.A. 2009. Evaluation of antioxidant activity of non-transformed and transformed pineapple: A comparative study. Food and Chemical Toxicology 47: 2696-2702.

Noci, F.; Riener, J.; Walking-Ribeiro, M.; Cronin, D.A.; Morgan, D.J. and Lyng, J.G. 2008. Ultraviolet irradiation and pulsed electric fields (PEF) in a hurdle strategy for the preservation of fresh apple juice. Journal of Food Engineering 85: 141-146.

Ranganna, S. 2003. Hand book of analysis and quality control for fruits and vegetables product. Tata McGraw-Hill publishing company limited. New delhi, 11-12 pp.

Sairi, M. 2005. The deacidification of pineapple juice using electrodialysis with monopolar ion exchange membranes. Johor, Malaysia: UniversitiTeknologi Malaysia, MSc thesis.

Shaw, P.E. 1992. Shelf life and aging of citrus juice, juice drinks and related soft drinks. In Redd, J.B., Shaw Ir, P.E., Hendrix, C.M. and Hendrix, D.L. (Eds). Quality control manual for citrus processing, p. 173-199. Florida, Auburndale: Agscience.

Tahiri, L.; Makhlouf, J.; Paquin, P. and Fliss, I. 2006. Inactivation of food spoilage and Escherichia coli $0157: \mathrm{H7}$ in phosphate buffer and orange juice using dynamic high pressure. Food Research International 39: 98-105.

Tiwari, R.B. (2000). Studies on blending of guava and papaya pulp for RTS beverages. Indian Food Packer, 54: 68.

Tournas, V.H.; Heeres, J. and Burgess, L. 2006. Moulds and yeasts in fruit salads and fruit juices. Food Microbiology 23: 684-688.

Vasavada, P.C. 2003. Microbiology of fruit juice and beverages. In Foster, T. and Vasavada, P.C. (Eds). Beverage quality and safety, p. 95-123. USA: CRC Press. 